\title{
Dysphagia aortica
}

\author{
Serena Grimaldi · Pamela Milito · Andrea Lovece · Emanuele Asti · Francesco Secchi · Luigi Bonavina (D)
}

Received: 9 October 2021 / Accepted: 11 October 2021 / Published online: 9 November 2021

(C) The Author(s) 2021

\begin{abstract}
Summary
Background Dysphagia aortica is an umbrella term to describe swallowing obstruction from external aortic compression secondary to a dilated, tortuous, or aneurysmal aorta. We performed a systematic literature review to clarify clinical features and outcomes of patients with dysphagia aortica.
\end{abstract}

Materials and methods We searched PubMed, EMBASE, Web of Science, and the Cochrane Library. The terms "aortic dysphagia," "dysphagia aortica," "dysphagia AND aortic aneurysm" were matched. We also queried the prospectively updated database of our esophageal center to identify patients with aortic dysphagia referred for diagnosis and treatment over the past two decades.

Results A total of 57 studies including 69 patients diagnosed with dysphagia aortica were identified, and one patient from our center was added to the database. The mean age was 72 years (range 22-98), and the male to female ratio $1.1: 1$. Of these 70 patients, the majority $(n=63,90 \%)$ had an aortic aneurysm, pseudoaneurysm, or dissection. Overall, 37 (53\%) patients received an operative treatment $(81.1 \%$ a vascular procedure, $13.5 \%$ a digestive tract procedure, $5.4 \%$ both procedures). Thoracic endovascular aortic repair (TEVAR) accounted for $60 \%$ of all vascular procedures. The postoperative mortality rate was $21.2 \%(n=7 / 33)$.

S. Grimaldi, MD · P. Milito, MD · A. Lovece, MD · E. Asti, MD · F. Secchi, MD · Prof. L. Bonavina, MD ( $\square)$

Department of Biomedical Sciences for Health, Division of General and Foregut Surgery, IRCCS Policlinico San Donato, University of Milan, Piazza Edmondo Malan, San Donato Milanese, 20097 Milan, Italy

Luigi.bonavina@unimi.it

F. Secchi, MD

Department of Radiology, IRCCS Policlinico San Donato, University of Milan, Milan, Italy
The mortality rate among patients treated conservatively was $55 \%$ ( $n=11 / 20)$. Twenty-six $(45.6 \%)$ studies were deemed at a high risk of bias.

Conclusion Dysphagia aortica is a rare clinical entity with high morbidity and mortality rates and no standardized management. Early recognition of dysphagia and a high suspicion of aortoesophageal fistula may be lifesaving in this patient population.

Keywords Aortic dysphagia - Thoracic aortic aneurysm · Aortic pseudoanaeurysm - TEVAR · Aortoesophageal fistula

\section{Main novel aspects}

- There is lack of evidence regarding definition, interpretation and management of aortic dysphagia.

- Most patients reported in the literature were diagnosed with aortic aneurysm, pseudoaneurysm, or dissection.

- Underestimation of dysphagia in this patient population may lead to death from aortoesophageal fistula.

\section{Introduction}

Dysphagia is a common symptom reported by $10-33 \%$ of elderly individuals in the community and nursing home settings [1, 2], although the true prevalence is likely underestimated because many patients adapt through behavioral changes [3]. The most frequent causes are neurogenic, mechanical obstruction, primary motility disorder, or external compression. The term dysphagia aortica was first introduced by Pape [4] in 1932 to describe dysphagia caused by external aortic compression from an aneurysmal, dilated, or tortuous aorta [5]. In 1997, Wilkinson wrote, "The condition of dysphagia aortica is reminiscent of the Churchillian paraphrase-a riddle wrapped in a mys- 
tery inside an enigma" [6]. Dysphagia aortica is rarely mentioned in standard gastroenterological and surgical textbooks and has received little attention in the literature. Dysphagia arises when the aorta pushes the esophagus anterolaterally and against the crural diaphragm. Primary aortoesophageal fistula (AEF) is the most feared complication [7], typically in the setting of untreated thoracic aortic aneurysm (TAA) that occurs in 5-10 per 100,000 person years [8]. This may be asymptomatic and diagnosed incidentally, or it may present with symptoms due to mediastinal compression or with dissection or rupture in the worst-case scenario. Secondary AEF can occur after surgical or endovascular repair of thoracic aortic aneurysms. The typical presentation of AEF was first described by Chiari [9] as a triad of chest pain, sentinel hematemesis, and final massive hemorrhage with exsanguination after a symptom-free interval.

To date, several single case reports of aortic dysphagia have been reported, the majority in women over 70 years old with short stature, hypertension, and kyphoscoliosis [5], often in association with left ventricular enlargement and congestive heart failure [7]. The aim of the present study was to perform a literature review on dysphagia aortica, to add a case recently seen at our institution, and to highlight the diagnostic features and outcomes of this rare syndrome.

\section{Materials and methods}

A systematic literature review was conducted to identify patients with dysphagia aortica reported from 01 January 1997 to 31 December 2020 using the PubMed, EMBASE, Web of Science, and the Cochrane Library databases. The search was conducted according to the Preferred Reporting Items for Systematic Reviews and Meta-Analysis (PRISMA) statement [10]. The following MeSH terms were used: "dysphagia AND aortic aneurysm," "dysphagia aortica," and "aortic dysphagia." Two independent investigators (SG and PM) performed the literature search to identify all English-written reports. The full text of the selected studies was assessed by one investigator (SG) and classified as relevant, not relevant, or unclear. The reference lists of eligible studies were manually searched to identify additional studies. The methodological quality of the studies was assessed according to Murad et al. [11], based on a global evaluation of the most critical factors that increase the risk of bias in the specific clinical context. Disagreements at either stage were solved by discussion and arbitrated by a senior author (LB).

Data extracted included first author name, country, year of publication, number of patients included in the report, age, sex, symptoms at presentation, diagnostic methods, imaging findings, characteristics of the aneurysm, type of treatment, and short- and longterm outcomes.

Fig. 1 PRISMA flowchart
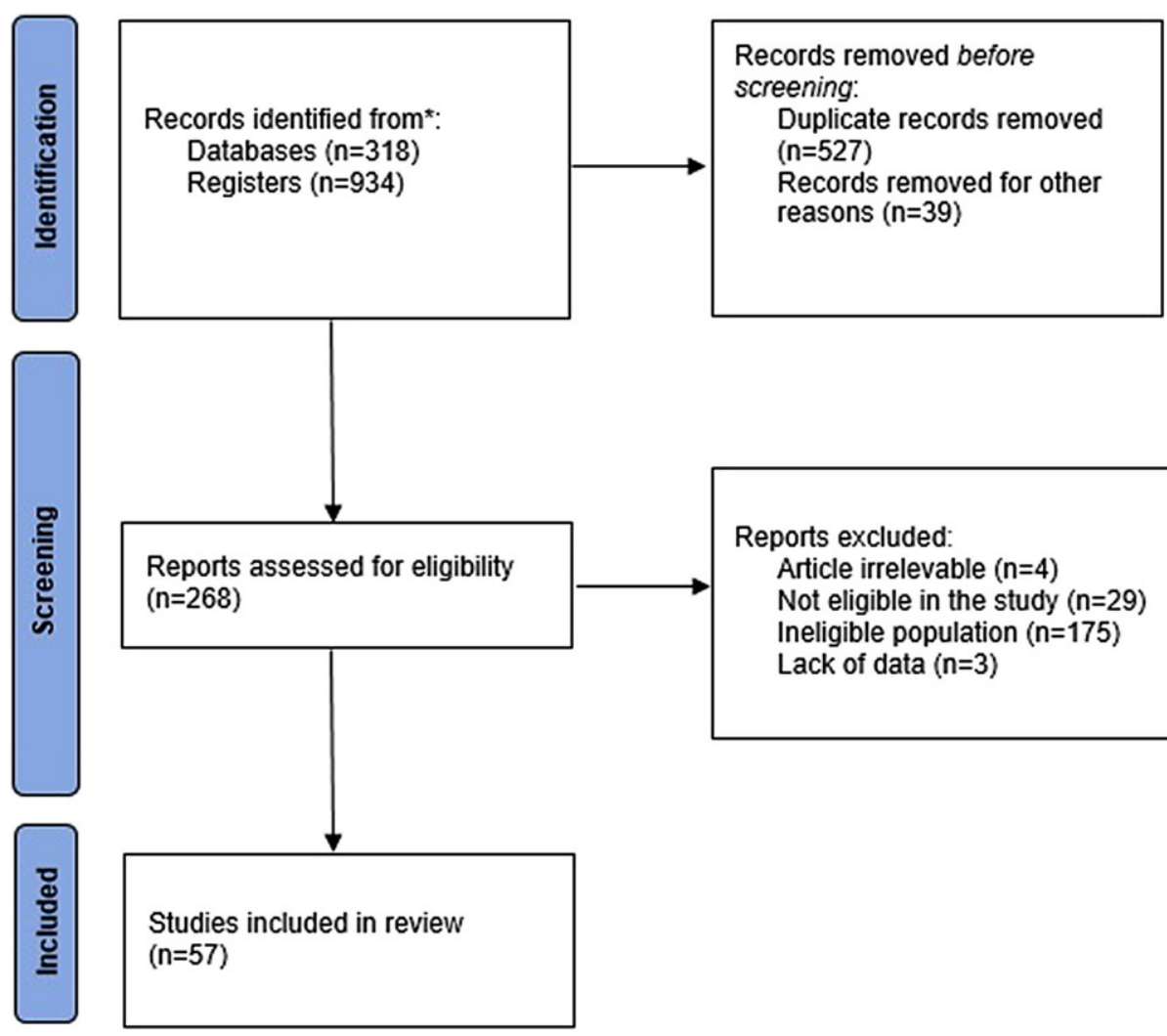

Reports excluded:

Article irrelevable $(n=4)$

Not eligible in the study $(n=29)$

Ineligible population $(n=175$ )

Lack of data $(n=3)$ 


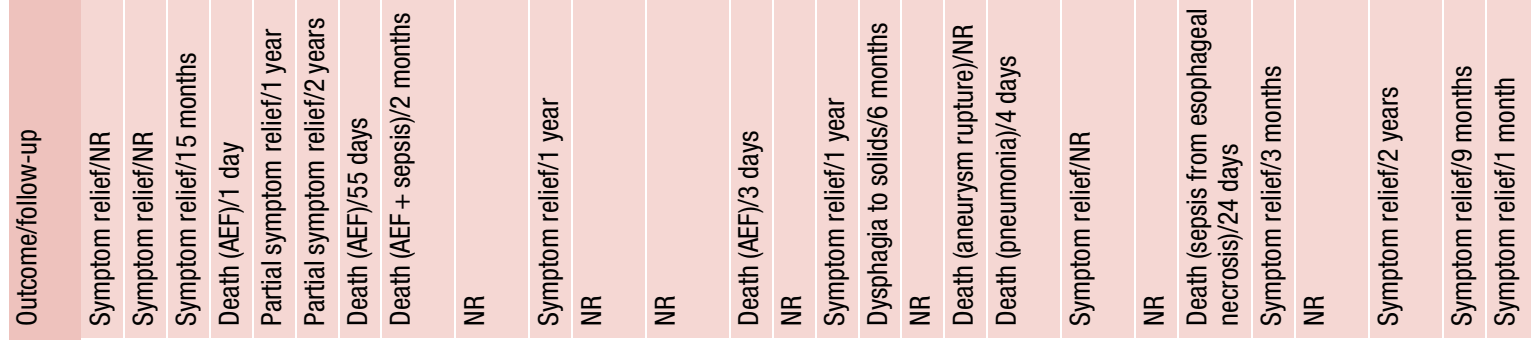

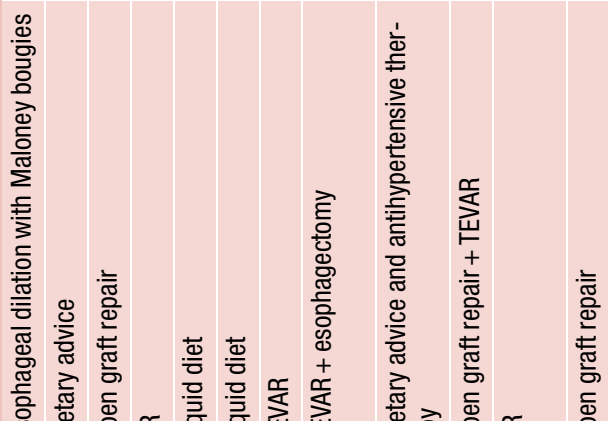

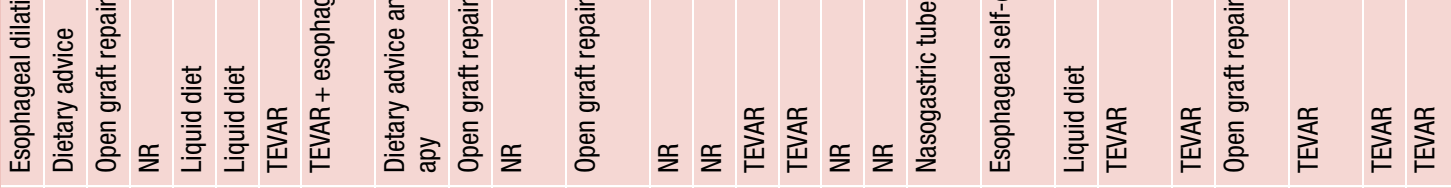

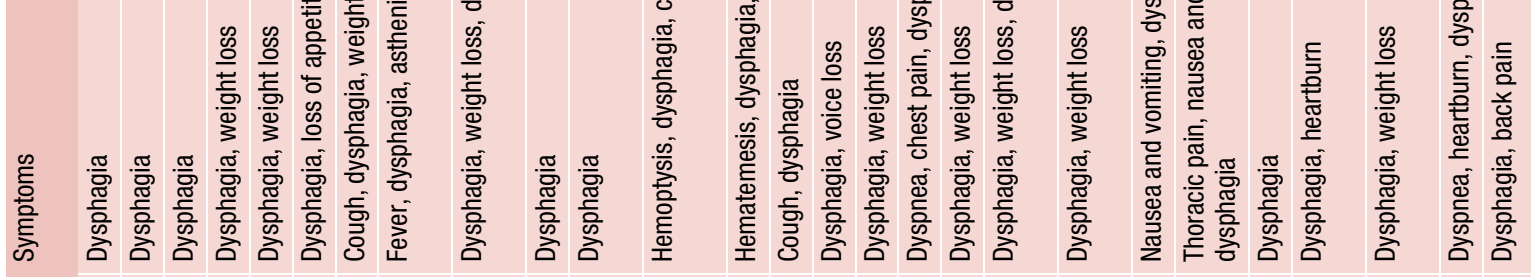

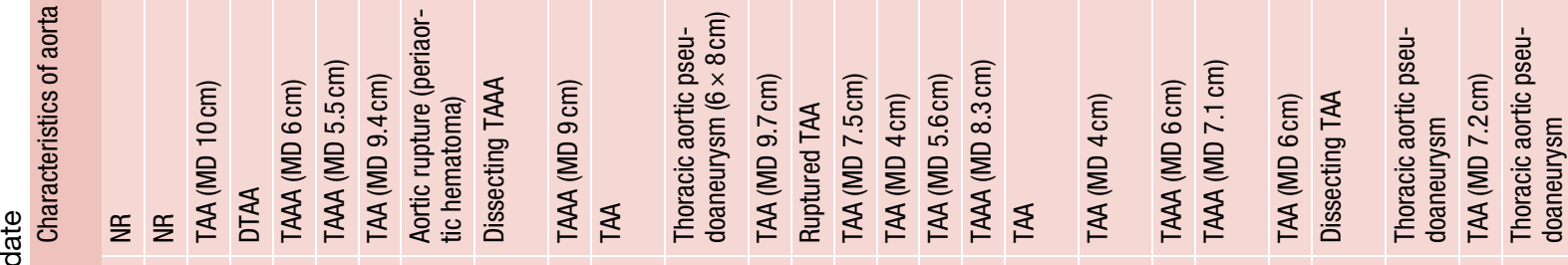

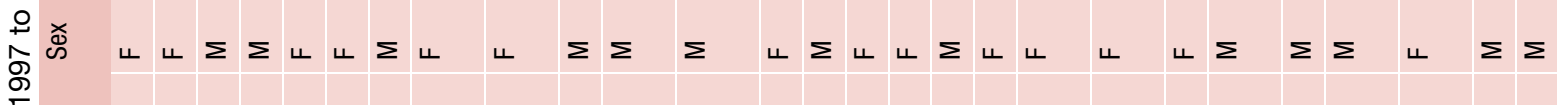

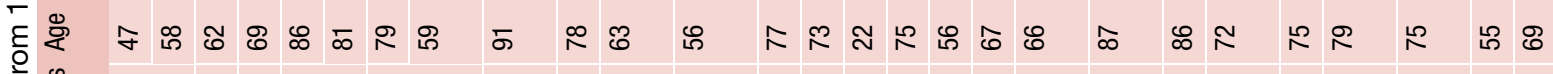

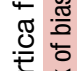

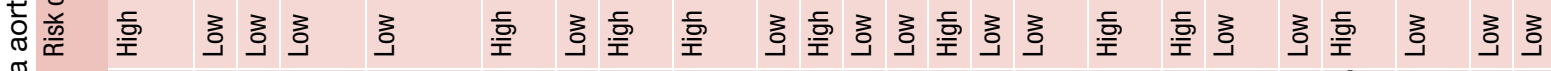

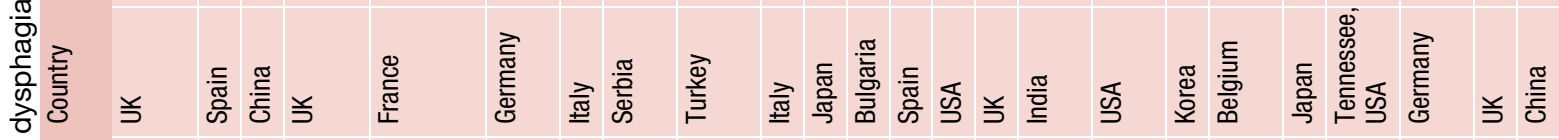

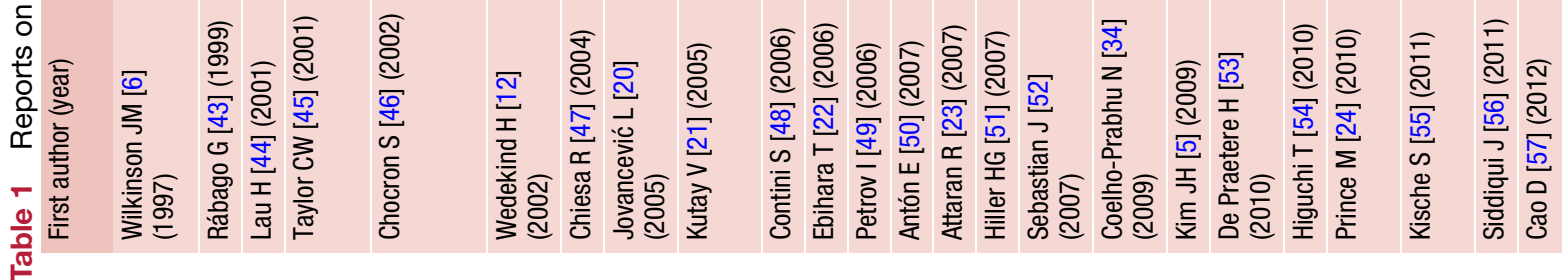



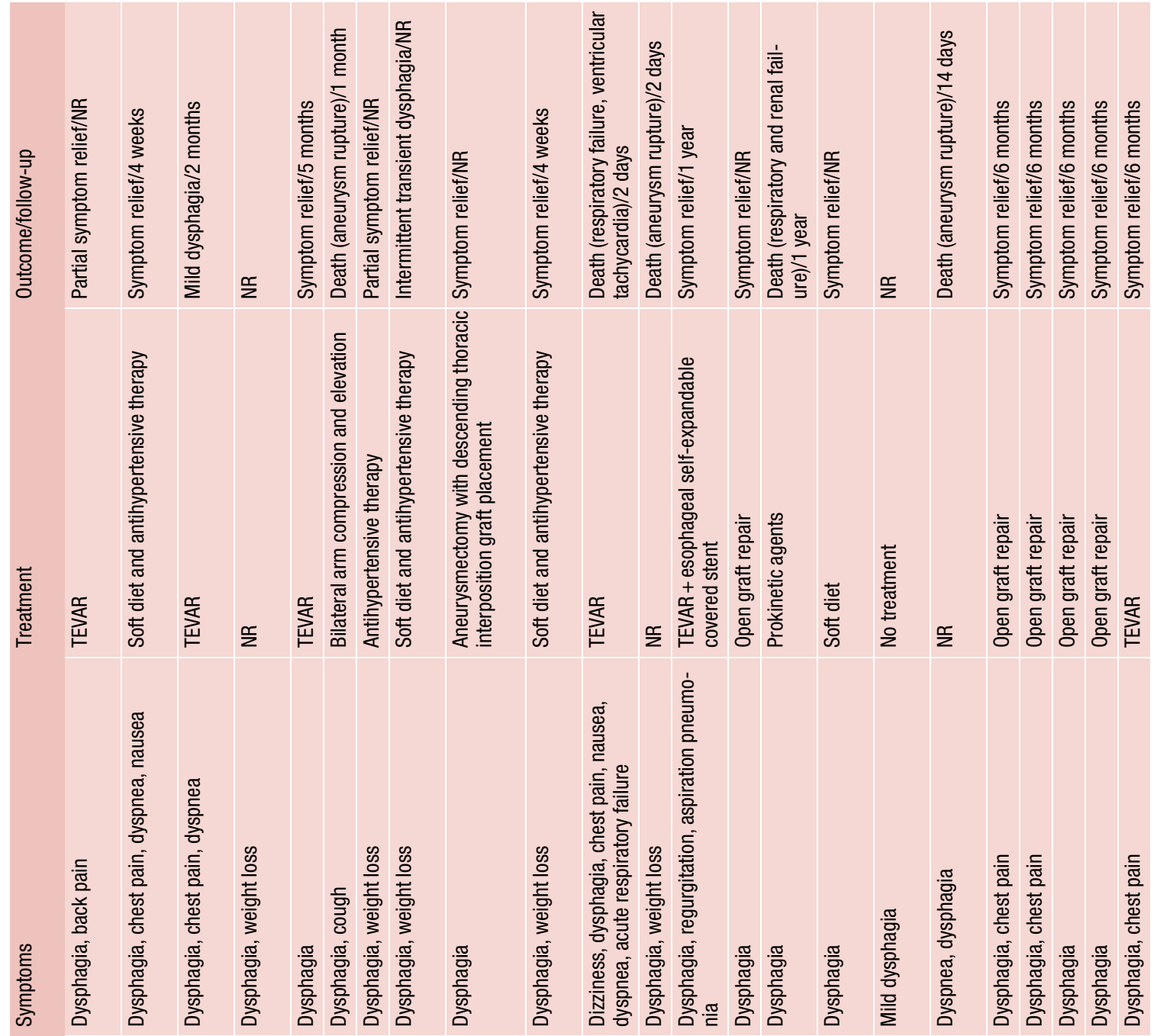

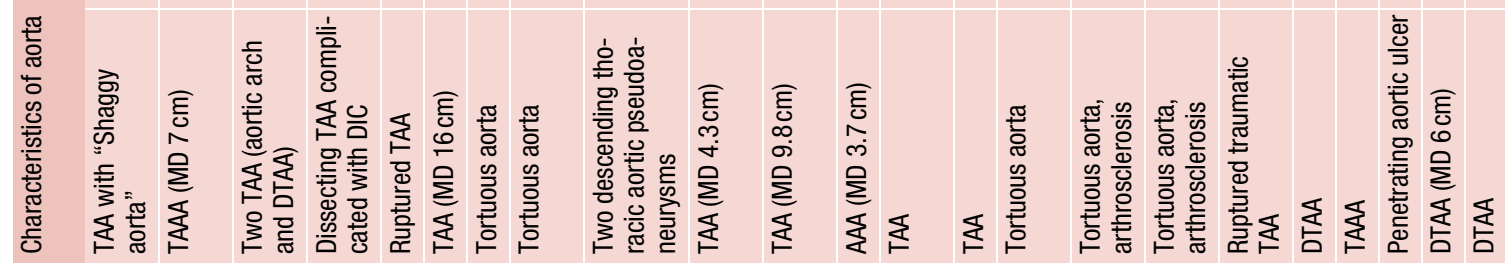

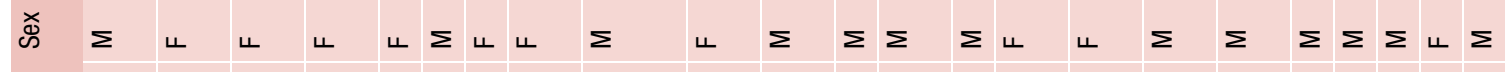

远

$\stackrel{\frac{\mathscr{c}}{0}}{\frac{\pi}{0}}$

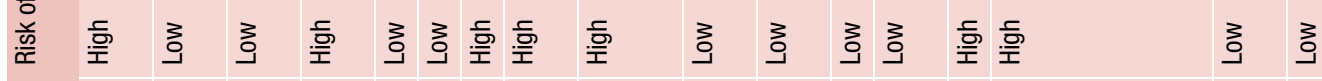

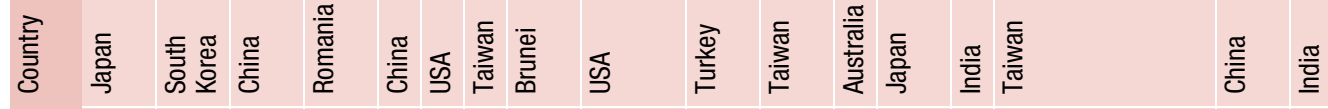

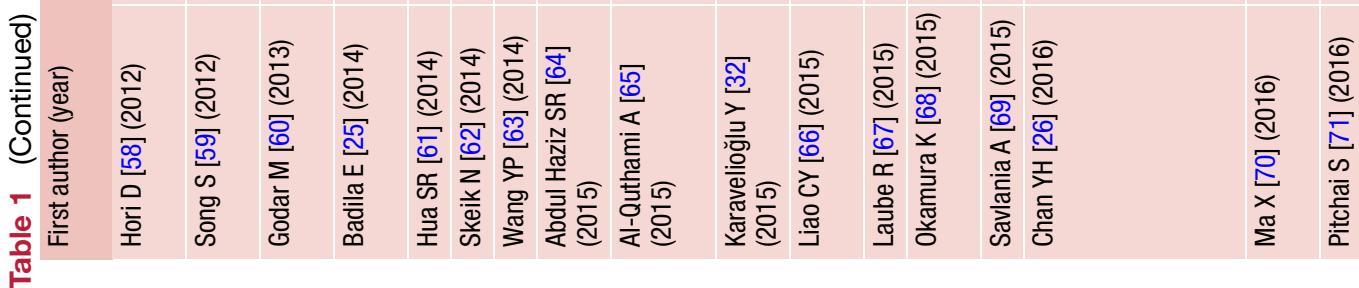




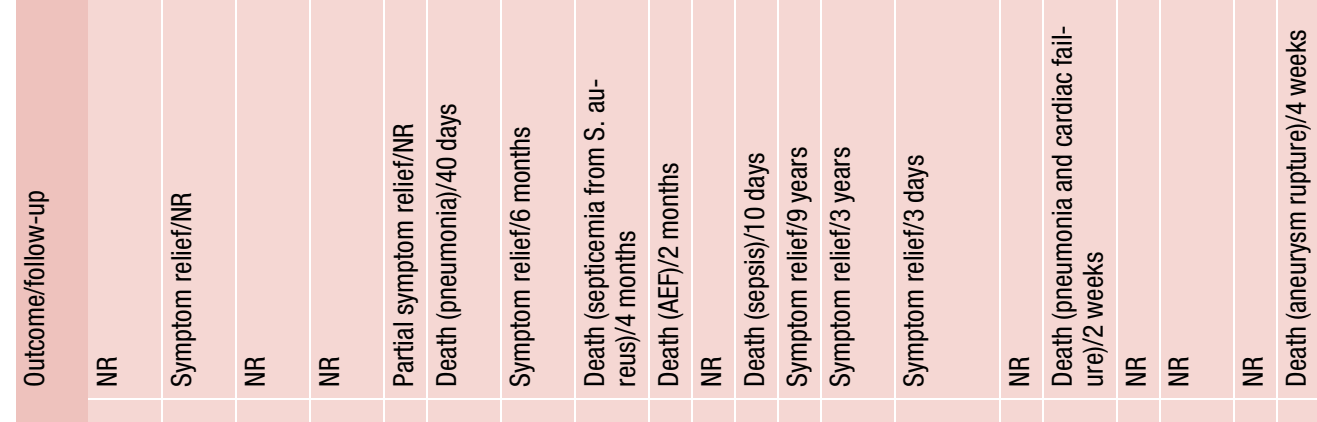
竞

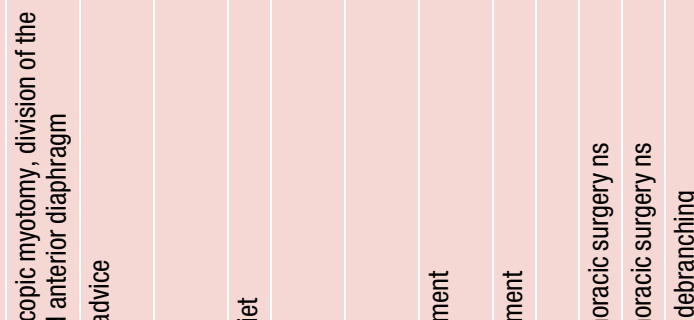

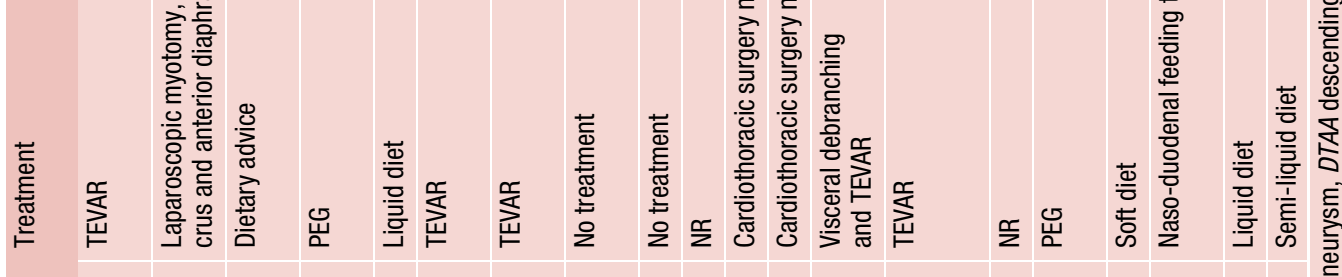

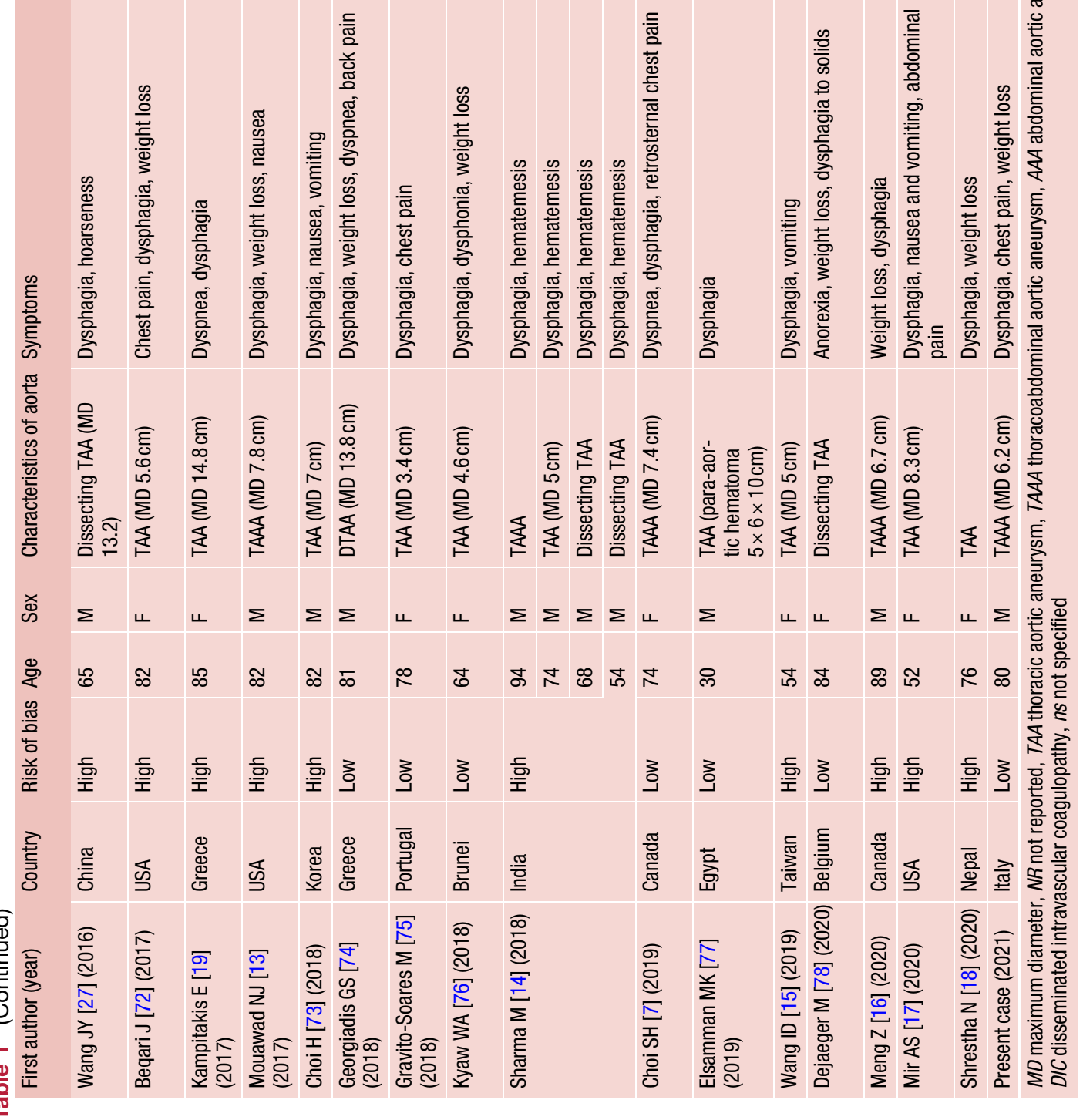


The prospectively updated database of our tertiary care esophageal center was also queried to identify all patients with dysphagia as a predominant symptom referred for consultation between 2002 and 2021.

\section{Results}

\section{Literature review}

The search strategy identified 1252 articles (918 from registers and 318 records from databases). After duplicates were removed, 725 records were screened. Two reviewers independently screened the titles and abstracts of all papers, leading to exclusion of 984 records. A total of 57 studies were eligible for analysis (Fig. 1). There was a total of 70 patients, 33 women and 37 men, with a median age of 72 years (range 22-98). Dysphagia was associated with aortic aneurysm $(n=53)$, aortic dissection $(n=7)$, tortuous aorta $(n=5)$, or aortic pseudoaneurysm $(n=3)$. The main patient characteristics are summarized in Table 1. All patients complained of intermittent or chronic dysphagia associated with weight loss in $32.9 \%$ of cases, chest pain in $18.6 \%$, and dyspnea in $15.7 \%$. About half of the patients $(n=33,47.1 \%)$ were considered unfit for any endoscopic or surgical approach due to elderly age and multiple comorbidities, and were mainly treated conservatively with antihypertensive therapy and a modified oral diet or through a feeding tube.

The majority $(53 \%)$ of patients underwent some form of vascular, digestive tract, or combined endoscopic or surgical procedure (Table 2). A vascular procedure was performed in 30 patients and consisted of thoracic endovascular aortic repair (TEVAR) in 18, open aneurysm repair in 11, and TEVAR plus open bypass graft in 1 patient. Relief of dysphagia was noted in 20 patients $(66.7 \%)$. Among the remaining patients, 5 died, 2 complained of persistent dysphagia, and 3 were lost to follow-up.

Table 2 Type of surgical and endoscopic procedures performed in 37 patients with dysphagia aortica

\begin{tabular}{|l|l|l|}
\hline Vascular procedure & \multicolumn{1}{l|}{$n$} & Mortality \\
\hline TEVAR & 30 & $5 / 27$ \\
\hline Open aneurysm repair & 18 & \\
\hline TEVAR + bypass graft & 11 & \\
\hline Digestive tract procedure & 1 & \\
\hline PEG & 5 & $1 / 4$ \\
\hline Esophageal stent & 2 & \\
\hline Heller + crural myotomy & 1 & \\
\hline Esophageal dilation & 1 & \\
\hline Combined vascular and digestive procedure & 1 & \\
\hline TEVAR + esophageal stent & 2 & $1 / 2$ \\
\hline TEVAR + esophagectomy & 1 & \\
\hline TEVAR Thoracic Endovascular Aortic Repair & 1 & \\
\hline
\end{tabular}

Digestive tract procedures consisted of percutaneous endoscopic gastrostomy (PEG; $n=2$ ), endoscopic esophageal stent $(n=1)$, Maloney bougie dilation $(n=1)$, and laparoscopic Heller myotomy and crural myotomy $(n=1)$. The procedure was successful in 3 patients, 1 patient died, and 1 was lost to follow-up. Combined vascular and digestive procedures consisted of TEVAR and esophageal stent $(n=1)$ and TEVAR and esophagectomy. The latter was complicated by AEF and sepsis.

Follow-up data were missing for 17 (24.3\%) of the patients [5, 12-27]. For the remaining 53 patients, the median follow-up was 3 months (range 2 days -9 years) and the overall mortality rate $34 \%$. The 30 -day mortality rate after TEVAR and/or open aneurysm repair was $60 \%(3 / 5)$. The reported reasons for death were the following: aneurysm rupture $(n=5)$, aspiration pneumonia $(n=5)$, primary AEF $(n=3)$, secondary AEF $(n=2)$, and sepsis $(n=3)$. Based on the criteria of methodological quality proposed by Murad et al. [11], $26(45.6 \%)$ studies were considered to be at a high risk of bias.

\section{Case report}

An 80-year-old man, body mass index (BMI) $20.1 \mathrm{~kg} / \mathrm{m}^{2}$, non-smoker, was referred to our emergency department in November 2020 during the second wave of the COVID-19 pandemic. He complained of progressive dysphagia, chest pain, and $15 \mathrm{~kg}$ weight loss over the past 6 months. Medical history included appendectomy, prostatectomy, and prosthetic replacement of the ascending aorta via sternotomy in 2006. Laboratory tests showed hemoglobin $12.1 \mathrm{~g} / \mathrm{dL}$ (normal value [n.v.] $14-18 \mathrm{~g} / \mathrm{dL}$ ), total protein $5.95 \mathrm{~g} / \mathrm{dL}$ (n.v. 6.60-8.70 g/dL), albumin $3.1 \mathrm{~g} / \mathrm{dL}$ (n.v. $3.50-5.20 \mathrm{~g} / \mathrm{dL}$ ), C-reactive protein $12.6 \mathrm{mg} / \mathrm{dL}$ (n.v. $<0.5 \mathrm{mg} / \mathrm{dL}$ ). A transthoracic echocardiogram showed dilatation and systolic dysfunction of the left ventricle (ejection fraction 33\%), and mild aortic insufficiency.

A barium swallow study revealed a marked extrinsic compression at the level of the lower third of the esophagus, with a filiform contrast flow and dilatation above. Esophagogastroduodenoscopy confirmed a pulsatile extrinsic compression with luminal narrowing from $38 \mathrm{~cm}$ to $42 \mathrm{~cm}$ from the dental arch (Fig. 2). A computer tomography (CT) scan performed with oral contrast medium showed distal esophageal compression due to a giant thoracic aortic aneurysm (Fig. 3a). Magnetic resonance angiography (MRA) confirmed a giant aneurysm extending from the ascending aorta to the infrarenal region, with signs of intravascular thrombosis and perivascular reaction. The diameter of the aorta was $51 \times 57 \mathrm{~mm}$ in the ascending thoracic portion, $48 \times 46 \mathrm{~mm}$ at the aortic arch, $57 \times 62 \mathrm{~mm}$ in the mid-third of the descending aorta, and $36 \times 35 \mathrm{~mm}$ below the level of the renal arteries (Fig. 3b). 
Fig. 2 a Barium swallow study showing a thin transit of contrast due to aneurysm compression over the distal esophagus. b Upper gastrointestinal endoscopy showing pulsatile bulging from aortic compression
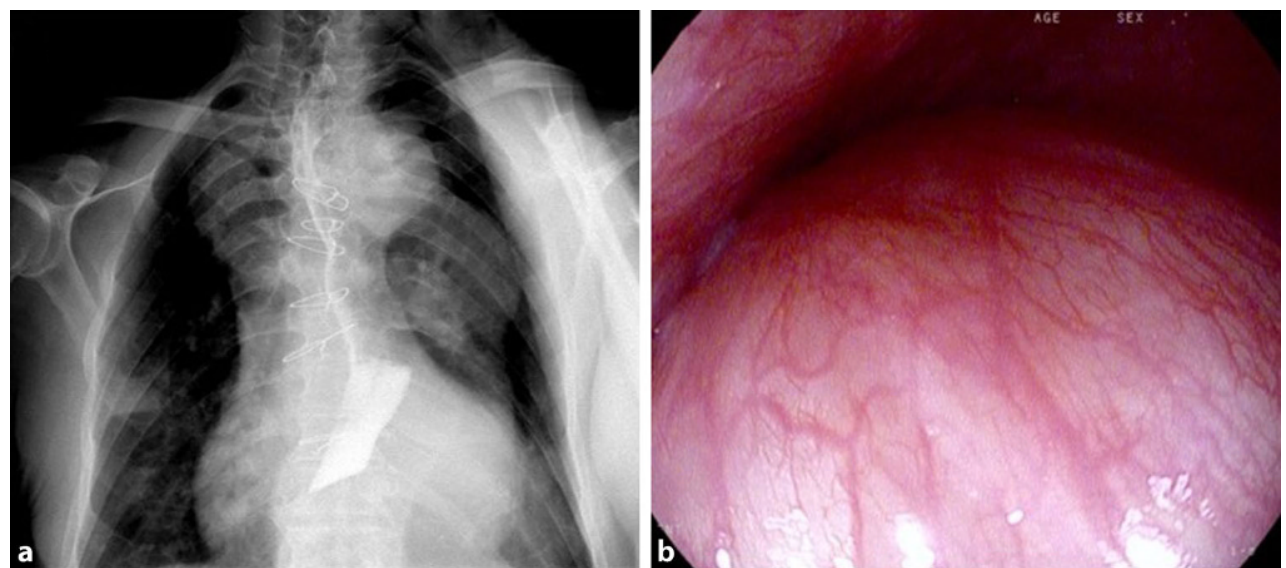

Fig. 3 a CT scan after oral contrast administration with maximum intensity projection reconstruction showing esophageal compression. b Magnetic resonance angiography after oral administration of gadoliniumbased contrast, showing the whole anatomy of the aortic aneurysm lumen with a virtual rendering technique
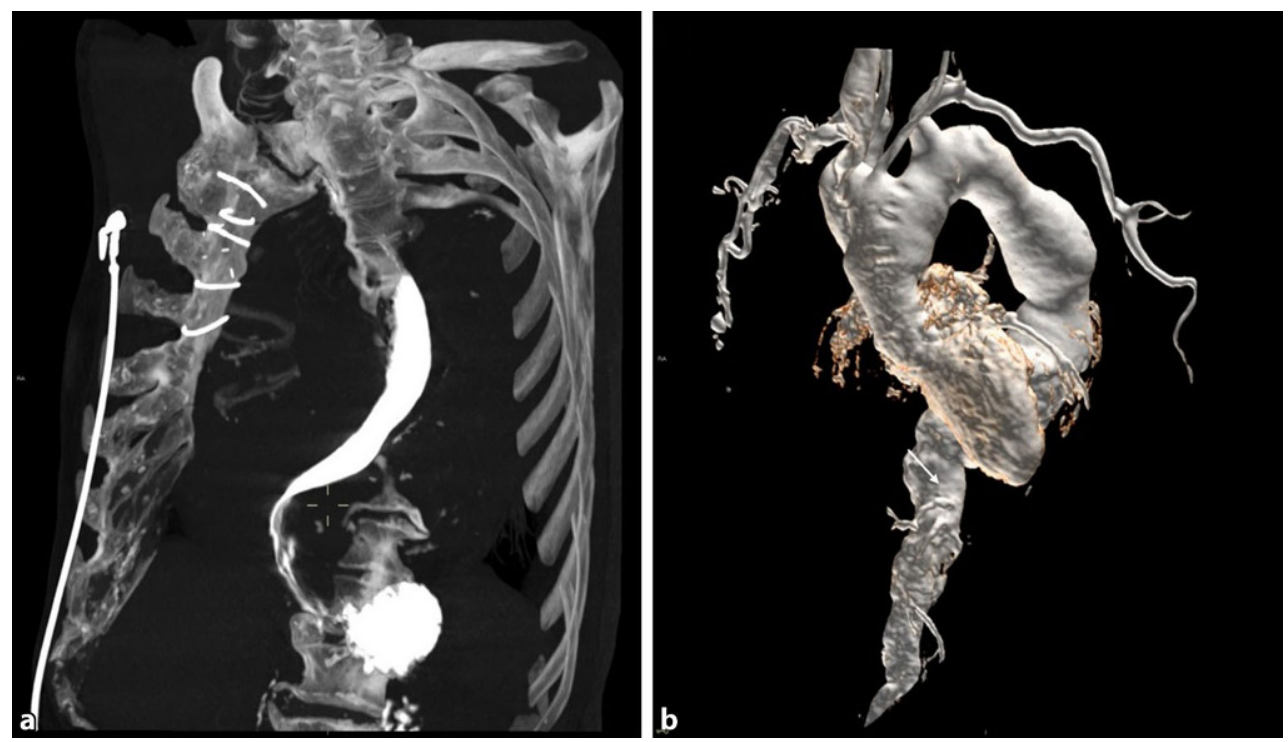

Fig. 4 a Thoracic CT scan showing right pulmonary consolidations as a sign of aspiration pneumonia. b Chest X-ray showing resolution of pneumonia
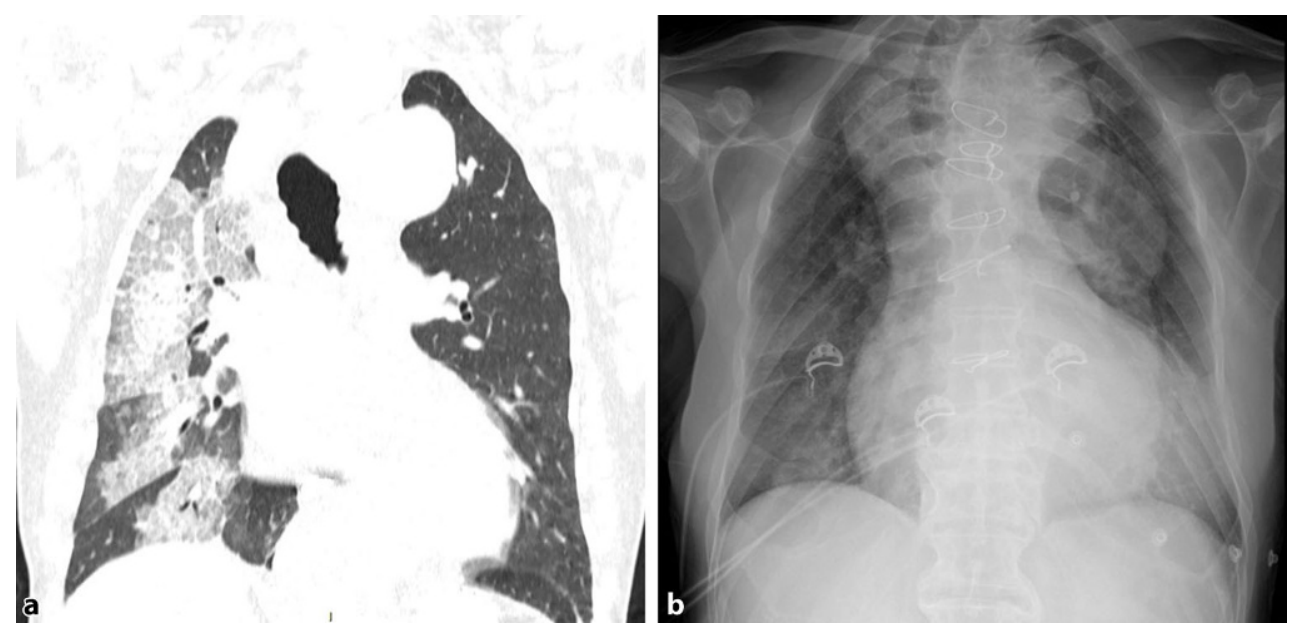

Based on the above findings, further diagnostic work-up with high-resolution esophageal manometry was considered to exclude concomitant achalasia. However, on the second day of the hospital stay, the patient acutely complained of dyspnea at rest with $90 \%$ of $\mathrm{SpO}_{2}$ in ambient air. Oxy- gen therapy was started at $2 \mathrm{~L} / \mathrm{min}$. Arterial blood gas analysis showed $\mathrm{pH}=7.43, \mathrm{pCO}_{2}=36.3 \mathrm{mmHg}$, $\mathrm{pO}_{2}=59.5 \mathrm{~mm} \mathrm{Hg}, \mathrm{HCO}_{3}=24 \mathrm{mmol} / \mathrm{L}$, and $\mathrm{sO}_{2}=89.1 \%$. Laboratory tests for Legionella pneumophila, Streptococcus pneumoniae, and SARS-CoV-2 RNA swab and IgG and IgM were negative. A chest CT scan revealed 


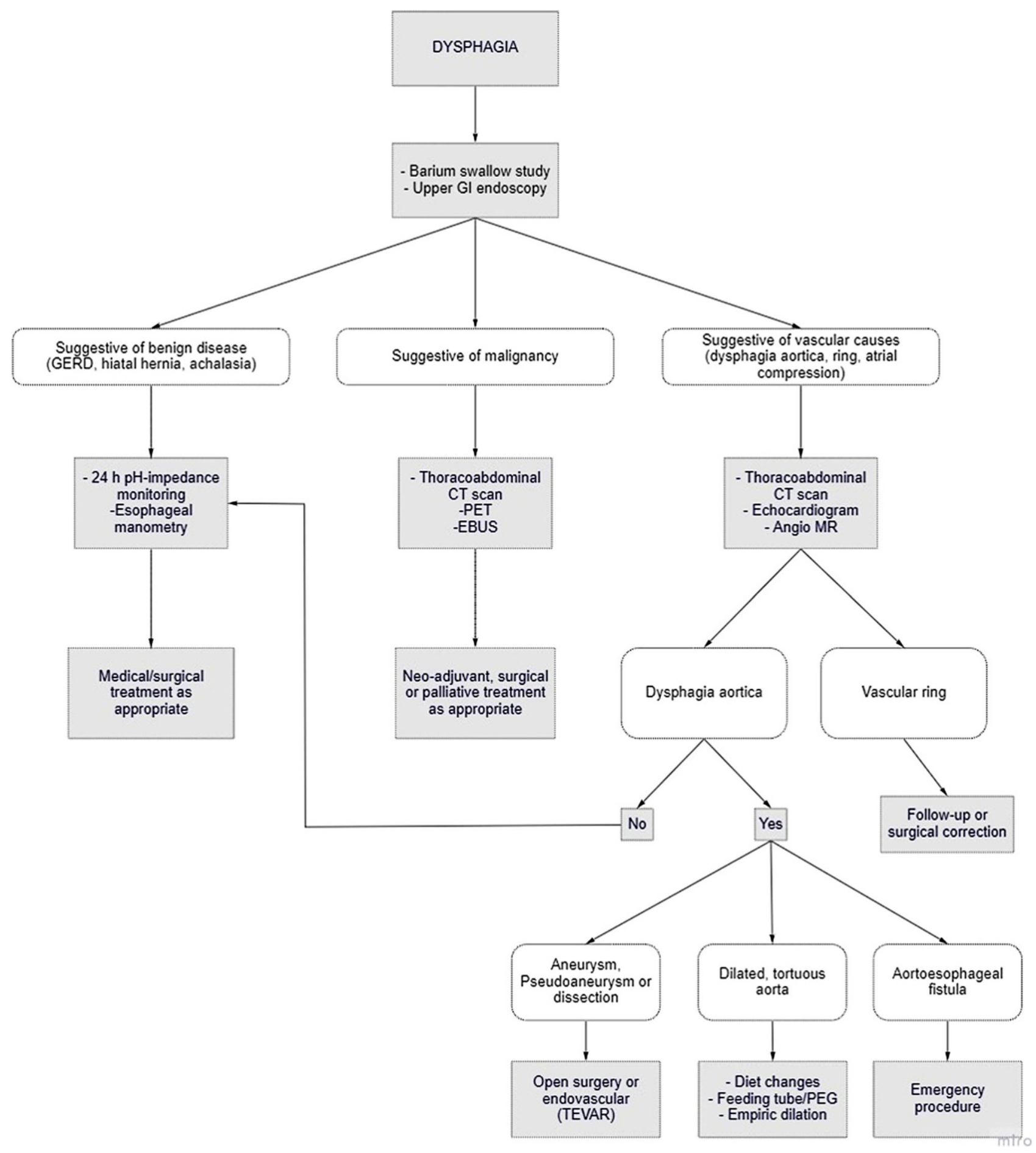

Fig. 5 Proposed management algorithm for patients with aortic dysphagia. GERD Gastroesophageal reflux disease, TEVAR Thoracic Endovascular Aortic Repair, PEG Percutaneous Endoscopic Gastrostomy

signs of right lung aspiration pneumonia. Antibiotic therapy was started (piperacillin/tazobactam $4.5 \mathrm{~g}$ four times a day) and oxygen therapy was increased (Venturi mask 35\%, 8L/min). Due to the increasing need of oxygen therapy, the patient was switched to continuous positive airway pressure (CPAP) therapy with significant improvement of SpO2. Oxygen flow was then progressively reduced and the chest X-ray after 2 weeks of antibiotic therapy revealed complete resolution of the clinical and radiologic pattern (Fig. 4).

The conclusion of a multidisciplinary board meeting including general and vascular surgeons was that the patient was unsuitable for vascular repair given his age, the multiple comorbidities, the low ejection fraction, and the aortic anatomy. The patient refused 
to undergo esophageal manometry. Therefore, enteral nutrition through a nasogastric tube or percutaneous endoscopic gastrostomy was recommended, but the patient declined any invasive procedure. He was then discharged on a semi-liquid diet. The patient died at home 4 weeks after hospital discharge due to probable aneurysm rupture.

\section{Discussion}

In the present systematic review, dysphagia aortica was associated with thoracic aortic aneurysm in most patients. Interestingly, 21 of 63 (33.3\%) patients underwent TEVAR as a single treatment modality or combined with other vascular or digestive tract procedures.

The prevalence of dysphagia aortica is neither well reported nor well studied [7]. It has been suggested that external compression of the esophagus may not represent the major pathophysiological mechanism, but rather an incidental finding. As in dysphagia lusoria, an underlying esophageal motility disorder may be present in some of these patients, particularly in those without evidence of aneurysm [28, 29]. It has also been speculated that long-lasting esophageal compression may evolve into esophageal pseudoachalasia, a rare condition accounting for less than $5 \%$ of patients with achalasia-like syndrome [30, 72, 78]. Reported findings at esophageal manometry are low-amplitude propagated peristaltic waves in the proximal esophagus and a localized high-pressure zone at the site of vascular compression. Wilkinson [6] investigated 5 patients complaining of dysphagia to solids associated with a localized high-pressure zone on esophageal manometry. None of the patients had an aneurysm, and videoradiographic assessment with a solid bolus supported the diagnosis of dysphagia aortica.

Considering the rarity of dysphagia aortica, there is no gold standard for diagnosis and therapy. A history of aortic aneurysm or prior aortic graft or TEVAR is key for diagnosis. Radiological and endoscopic imaging provides a high index of suspicion [5]. The diagnostic work-up should include chest X-ray, upper gastrointestinal endoscopy, barium or videofluoroscopic swallowing study, chest CT scan with oral and intravenous contrast, and esophageal manometry. No single diagnostic tool can definitively prove the diagnosis of dysphagia aortica. Radiographic findings may be inconclusive because a dilated and tortuous aorta is frequently seen in elderly patients in the absence of a true aneurysm. Upper gastrointestinal endoscopy has the potential to exclude other possible causes of upper gastrointestinal bleeding, and to detect signs of AEF such as small mucosal erosions, oozing from a pin-hole erosion, ulcer with adherent clot over a pulsatile mass, or graft exposure [31].

The treatment of dysphagia aortica depends on the severity of symptoms and the patient's comorbidi- ties. Most patients with mild and intermittent symptoms may be treated conservatively by a modified diet. Treatment of associated cardiac failure or arterial hypertension may also significantly reduce the burden of symptoms, especially in the case of small aneurysms [6, 32]. Percutaneous endoscopic gastrostomy, endoscopic esophageal dilation with bougie [6, 33], or an esophageal self-expandable stent have been used sporadically [34]. In the past, surgical procedures proposed to reduce esophageal compression included anterolateral transposition of the esophagus with posterior cruroplasty [33], and mobilization of the distal esophagus from the aortoesophageal decussation area with creation of a posterior pleural sling [35]. More recently, Heller myotomy with division of the right crus of the diaphragm to relieve esophageal compression [33-36] has also been reported. A proposed management algorithm for dysphagia aortica is shown in Fig. 5.

Aortic aneurysm is a progressive disease, and current practice guidelines recommend treatment of asymptomatic thoracic aortic aneurysms with diameter $\geq 55 \mathrm{~mm}$. Aortoesophageal fistula is a rare complication, representing less than $10 \%$ of all aortoenteric fistulas [37]. In 1991, Hollander and Quick [38] reviewed 500 patients with AEF and found that an untreated thoracic aortic aneurysm accounted for $54 \%$ of the cases. Since then, secondary AEF have become an increasingly recognized complication of surgical or endovascular repair of thoracic aortic aneurysms.

Direct open surgical aneurysm repair and TEVAR $[7,39]$ are the most common therapeutic options in patients who are fit for these procedures. Over the past 20 years, TEVAR has evolved into an upfront treatment option, showing the potential for preventing further aortic enlargement and ultimate aortic rupture. However, the fact that periaortic hematoma remains untreated may potentially aggravate dysphagia. In addition, further impingement of the esophagus by the hematoma or by an oversized stent, endoleak, stent migration, or a penetrating aortic ulcer can accelerate aortic rupture, AEF, and sepsis [40, 41].

In a large multicenter survey [42] including 1138 patients treated with TEVAR over a 10 -year period, 2 of 25 (8\%) patients with aortoesophageal or aortobronchial fistula presented with dysphagia. The interval between the first reported episode of sentinel hemorrhage and the final diagnosis ranged from $2 \mathrm{~h}$ to 6 months. Thirty-day mortality and actuarial 2-year survival were $28 \%$ and $54.7 \%$, respectively. A combined endovascular and surgical approach reduced infectious complications and recurrent fatal bleeding. Although the evidence was not strong enough to justify changes in clinical practice, the authors felt that this complication was underestimated even in large trials and questioned the utility of the endovascular approach as the exclusive therapeutic modality. 
Since the occurrence of secondary AEF complicating TEVAR is unpredictable, it would be paramount to establish the criteria for an early diagnosis. Unfortunately, the association of dysphagia with thoracic aortic aneurysm remains elusive in most reported series, often because the symptom is mild, intermittent, or neglected by both the patient and the physician. Further studies are needed to establish the prevalence of subclinical dysphagia aortica by using specific symptom questionnaires before and after aneurysm repair. Moreover, dysphagia should be rightfully included in the Chiari's triad that originally reported chest pain as the initial manifestation of AEF [9], as well as in clinical practice guidelines [40, 79]. Interestingly, the interval between the onset of dysphagia and bleeding from AEF exceeded 1 month in the few reported patients [48]. It is possible that with increasing worldwide adoption of the endovascular procedures, the reported incidence of dysphagia and AEF may increase as well [80]. This may temper the enthusiasm for TEVAR, which should instead represent a bridge to definitive aortic and esophageal reconstruction in patients who are fit for a staged procedure.

This review has several limitations, including reporting bias and the fact that all studies were case reports including up to 5 patients. Therefore, a significant gap in clinical evidence for both diagnostic and therapeutic outcomes remains due to the heterogeneity and the average low methodological quality of the case reports.

\section{Conclusion}

Dysphagia aortica is a rare entity with a high mortality rate and no standardized management. Lack of awareness and symptom underestimation may contribute to diagnostic delay. A thorough investigation is recommended to exclude other causes of dysphagia. With modern diagnostic technologies, dysphagia aortica should no longer represent an clinical enigma. One- or two-stage aneurysm repair is feasible in selected patients and may prevent AEF. Surveillance of patients with thoracic aortic aneurysms, early recognition of dysphagia, and a high suspicion of AEF may be lifesaving.

Funding Work supported by A.I.R.ES. (Associazione Italiana Ricerca ESofago).

Funding Open access funding provided by Università degli Studi di Milano within the CRUI-CARE Agreement.

\section{Declarations}

Conflict of interest S. Grimaldi, P. Milito, A. Lovece, E. Asti, F. Secchi, and L. Bonavina declare that they have no competing interests.

Ethical standards All procedures performed in studies involving human participants or on human tissue were in accordance with the ethical standards of the institutional and/or national research committee and with the 1975 Helsinki declaration and its later amendments or comparable ethical standards. Informed consent was obtained from all individual participants included in the study. Internal review board approval HSD 2021-087.

Open Access This article is licensed under a Creative Commons Attribution 4.0 International License, which permits use, sharing, adaptation, distribution and reproduction in any medium or format, as long as you give appropriate credit to the original author(s) and the source, provide a link to the Creative Commons licence, and indicate if changes were made. The images or other third party material in this article are included in the article's Creative Commons licence, unless indicated otherwise in a credit line to the material. If material is not included in the article's Creative Commons licence and your intended use is not permitted by statutory regulation or exceeds the permitted use, you will need to obtain permission directly from the copyright holder. To view a copy of this licence, visit http://creativecommons.org/licenses/by/4.0/.

\section{References}

1. Cho SY, Choung RS, Saito YA, et al. Prevalence and risk factors for dysphagia: a USA community study. Neurogastroenterol Motil. 2015;27:212-9.

2. Patel DA, Krishnaswami S, Steger E, et al. Economic and survival burden of dysphagia among inpatients in the United States. Dis Esophagus. 2018;31:1-7.

3. Ekberg O, Hamdy S, Woisard V, et al. Social and psychological burden of dysphagia: its impact on diagnosis and treatment. Dysphagia. 2002;17:139-46.

4. PapeR.Uber einenabnormenverlauf('tiefeRechtslage') der mesa aotitischen aorta descendens. Fortschr Roetgenstr. 1932;46:257-69.

5. Kim JH, Jang SW, KimDB, et al. A patient with dysphagia due to an aortic aneurysm. Korean Circ J. 2009;39:258-60.

6. Wilkinson JM, Euinton HA, Smith LF, et al. Diagnostic dilemmas in dysphagia aortica. Eur J Cardiothorac Surg. 1997;11:222-7.

7. Choi SHJ, Yang GK, Gagnon J, et al. Dysphagia aortica secondary to thoracoabdominal aortic aneurysm resolved after endograft placement. J Vasc Surg Cases Innov Tech. 2019;5:501-5.

8. MathurA, Mohan V,Ameta D, etal. Aortic aneurysm. JTransl IntMed. 2016;4:35-41.

9. Chiari H. Ueber Fremdkorperverletzung des Oesophagus mitAortenperforation. Berl Klin Wschr. 1914;51:7-9.

10. Page MJ, McKenzie JE, Bossuyt PM, et al. The PRISMA 2020 statement: an updated guideline for reporting systematic reviews. BMJ. 2021; https://doi.org/10.1136/bmj.n71.

11. Murad MH, Sultan S, Haffar S, et al. Methodological quality and synthesis of case series and case reports. BMJ Evid Based Med. 2018;23:60-3.

12. Wedekind H, Bisping G, Attaie T, et al. Differential diagnosis of "dysphagia" in an elderly woman. Clin Cardiol. 2002;25:132.

13. Mouawad NJ, Ahluwalia GS. Dysphagia in the aging cardiovascular patient. JThorac Dis. 2017;9:E1005-E8.

14. Sharma M, Singh P, Kirnake V, et al. Dysphagia aortica: emerging role of endoscopic ultrasound (with videos). Endosc Ultrasound. 2018;7:343-6.

15. Wang I-D, Huang H-K, Tsai P-Y, et al. Dysphagia aortica. QJM. 2019;112:137-8. 
16. Meng Z, Pereira M, Sharma A. An 89-year-old man with dysphagia due to an aortic aneurysm and enlarged left atrium. CMAJ. 2020;192:200427.

17. Mir AS, Kesar V, Nguyen VQ. Dysphagia aortica. Indian J Gastroenterol. 2020;39:524-5.

18. Shrestha N, Karki B, Shrestha PS. Dysphagia aortica-a rare cause of dysphagia. Oxf Med Case Reports. 2020;2020:omaa4.

19. Kampitakis E, Kalogerakos PD. Giant thoracic aortic aneurysm manifested as dysphagia and dyspnea. Ann Thorac Surg. 2017;103:e87. https://doi.org/10.1016/j. athoracsur.2016.06.100.

20. Jovancević L, Jović R, MitrovićSM. Dysphagia aortica—case report. Med Pregl. 2005;58:401-4.

21. Kutay V, Harman M, Ekim H, Yakut C. Chronic pseudoaneurysm of the aortic arch: a case report. J Card Surg. 2005;20:542-4.

22. Ebihara T, Yamasaki M, Kubo H, Yamaya M. Dysphagia in a patient with rapidly enlarged thoracic aortic aneurysm. JAm Geriatr Soc. 2006;54:1294.

23. Attaran RR, Guarraia D. Ascending aortic aneurysminaman with scleroderma. Clin Rheumatol. 2007;26:1027-8.

24. Prince M. Image of the month. Dysphagia-unusual presentation. clin Gastroenterol Hepatol. 2010;8:A25.

25. Badila E, Bartos D, Balahura C, Daraban AM. A rare cause of dysphagia-dysphagia aortica-complicated with intravascular disseminated coagulopathy. Maedica (Bucur). 2014;9:83-7.

26. Chan Y-H, Hung C-Y, Shieh T-Y, et al. Nonaneurysmatic dysphagia aortica in the elderly: three case reports and literature review. Int J Gerontol. 2016;10:52-5.

27. Wang J-Y, Chen H, Su X, Zhang Z-P. Aortic dissection manifesting as dysphagia and hoarseness: Ortner's syndrome. AmJ Emerg Med. 2016;34:1185.e1-1185.e3.

28. Dantas RO, de Godoy RA, Meneghelli UG, de Oliveira RB, Troncon LE. Dysphagia lusoria and segmental aperistalsis in the upper third of the esophagus. J Clin Gastroenterol. 1985;7:522-4.

29. Morgan AA, Mourant AJ. Left vocal cord paralysis and dysphagia in mitral valve disease. Br HeartJ. 1980;43:470-3.

30. Bonavina L, Bona D, Saino G, Clemente C. Pseudoachalasia occurring after laparoscopic Nissen fundoplication and crural mesh repair. Langenbecks Arch Surg. 2007;392:653-6.

31. Sosnowik D, Greenberg R, Bank S, Graver LM. Aortoesophageal fistula: early and late endoscopic features. Am J Gastroenterol. 1988;83:1401-4

32. Karavelioğlu Y, Kalçik M, Yetim M, SarakT, Bekar L, Doğan T. A rare cause of dysphagia and weight loss in a nonagenarian with hypertension: dysphagia aortica. J Am Geriatr Soc. 2015;63:1488-9.

33. McMillan IK, Hyde I. Compression of the oesophagus by the aorta. Thorax. 1969;24:32-8.

34. Coelho-Prabhu N, Baron TH. Dysphagia and weight loss in an elderly person. Dysphagia aortica. Gastroenterology. 2009; 137:e1-2.

35. Mittal RK, Siskind BN, Hongo M, Flye MW, McCallum RW. Dysphagia aortica. Clinical, radiological, and manometric findings. Dig Dis Sci. 1986;31:379-84.

36. Beachley MC, Siconolfi EP, Madoff HR, Chaudhry RM. Dysphagia aortica. Dig Dis Sci. 1980;25:807-10.

37. Sinar DR, DeMaria A, Kataria YP, et al. Aortic aneurysm eroding the esophagus. Case report and review. Am J Dig Dis. 1977;22:252-4.

38. Hollander JE, Quick G. Aortoesophageal fistula: a comprehensive review of the literature. Am J Med. 1991;91:279-87.
39. Hanna A, Derrick JR. Dysphagia caused by tortuosity of the thoracic aorta. J Thorac Cardiovasc Surg. 1969;57:134-7.

40. Hiratzka LF, Bakris GL, Beckman JA, et al. 2010 ACCF/AHA/AATS/ACR/ASA/SCA/SCAI/SIR/STS/SVM guidelines for the diagnosis and management of patients with thoracic aortic disease: a report of the American college of cardiology foundation/American heart association task force on practice guidelines, American association for thoracic surgery, American college of radiology, American stroke association, society of cardiovascular anesthesiologists, society for cardiovascular angiography and interventions, society of interventional radiology, society of thoracic surgeons, and society for vascular medicine. Circulation. 2010;121:e266-369.

41. Schemerhorn ML, Jones DW. Management of descending thoracic aorta disease: evolving treatment paradigms in the TEVAR era. Eur J Vasc Endovasc Surg. 2017;53:1-3.

42. Chiesa R, Melissano G, Marone EM, et al. Endovascular treatment of aortoesophageal and aortobronchial fistulae. JVasc Surg. 2010;51:1195-202.

43. Rábago G, Martín-Trenor A, López-Coronado JL. Chronic aneurysm of the descending thoracic aorta presenting with right pleural effusion and left phrenic paralysis. Tex Heart Inst J. 1999;26:96-8.

44. Lau H. Dysphagia aortica: Harbinger of aortoesophageal fistula? Surgery. 2001;129:763-4.

45. Taylor CW, Sinha A, Nightingale JMD. Dysphagia and thoracoabdominal aneurysm. Postgrad Med J. 2001;77:257-8.

46. Chocron S, Stoica L, Koch S, et al. Is endovascular stent grafting for descending thoracic aortic disease recommendable in patients with dysphagia? J Thorac Cardiovasc Surg. 2002;124:1239-41.

47. Chiesa R, Melissano G, Civilini E, et al. Two-stage combined endovascular and surgical approach for recurrent thoracoabdominal aortic aneurysm. J Endovasc Ther. 2004;11:330-3.

48. Contini S, Corrente V, Nervi G, et al. Dysphagia aortica: a neglected symptom of aortoesophageal fistula. Dig Liver Dis. 2006;38:51-4.

49. Petrov I, Nedevska M, Chilingirova N, et al. Endovascular repair of dissecting thoracic aortic aneurysm in a patient with Turner syndrome. JEndovasc Ther. 2006;13:693-6.

50. Antón E. Dysphagia aortica: a diagnostic challenge in the elderly. RevEspEnferm Dig. 2007;99:362-4.

51. Hiller HG, Lagattolla NRF. Thoracic aortic aneurysm presenting with dysphagia: a fatal delay in diagnosis. Thorac Surg Sci. 2007;4:Doc1.

52. Sebastian J, Kirankumar VS, Pappachan JM, et al. Multifactorial dysphagia complicated by esophago-bronchial fistula. JCancer Res Ther. 2007;3:108-10.

53. De Praetere H, Lerut P, Johan M, et al. Esophageal necrosis after endoprosthesis for ruptured thoracoabdominal aneurysm type I: can long-segment stent grafting of the thoracoabdominal aorta induce transmural necrosis? Ann VascSurg. 2010;24:1137.e7-1137.12.

54. Higuchi T, Takahashi T, Ishizaka T, et al. Rapid expansion of another downstream aortic aneurysm with the elephant trunk. Gen Thorac Cardiovasc Surg. 2010;58:617-9.

55. Kische S, Werner D, Ince H. A neglected symptom of contained aortic laceration-dysphagia aortica successfully treated by endovascular stentgrafting. Catheter Cardiovasc Interv. 2012;80:1052-5.

56. Siddiqui J, Hughes F. Dysphagia due to thoracic aortic aneurysm, relieved by thoracic endovascular aneurysm repair: a case report and review of the literature. BMJ Case Rep. 2011; https://doi.org/10.1136/bcr.09.2011.4793. 
57. Cao D, Gao Y, Sun X, et al. Dysphagia aortica secondary to descending thoracic aortic pseudoaneurysm. Ann Thorac Surg. 2012;94:656.

58. Hori D, Yuri K, Noguchi K, et al. Case report: successful endovascular treatment of saccular thoracic aneurysm with "shaggy aorta". Ann Thorac Cardiovasc Surg. 2012;18:536-9.

59. Song S, Chung J, Kim S. A case of dysphagia aortica in an elderly patient. IntJ Gerontol. 2012;6:46-8.

60. Godar M, Yuan Q, Zhang P, et al. Multiple thoracic aortic aneurysms and dysphagia aortica. Eur Heart J Cardiovasc Imaging. 2013;14:1026.

61. Hua S-R, Liu C-W, Zheng Y-H, et al. Dysphagia as the mere chief complaint of ruptured thoracic aneurysm in a patient with systemic lupus erythematosus. Ann Vasc Surg. 2014;28:1792.e1-1792.e3.

62. Skeik N, Ahmed AK, Schumacher CW, et al. Large thoracic aortic aneurysm and dissection with rare complication. Ann Vasc Surg. 2014;28:1034.e9-1034.e12.

63. Wang Y-P, Wu Y-C, Lu C-L. An octogenarian with dysphagia and weight loss. Clin Gastroenterol Hepatol. 2014;12:A27-8.

64. Abdul Haziz SR, Bickle I, Chong VH. Dysphagia aortica: a rare cause of dysphagia. BMJ Case Rep. 2015;2015:bcr2015211726. https://doi.org/10.1136/bcr2015-211726.

65. Al-Quthami A, Albloushi A, Alquthami AH. Images in vascular medicine. Dysphagia aortica with left atrial compression. Vasc Med. 2015;20:266-7.

66. Liao C-Y, Huang S-C, Wang Y-C, et al. Dysphagia aortica: a fatal delay in diagnosis. Am J Emerg Med. 2015;33:1117.e3-1117.e5.

67. Laube R, Liu K, Katelaris P. Education and imaging. Gastroenterology: dysphagia aortica. J Gastroenterol Hepatol. 2015;30:799.

68. Okamura K, Suematsu Y, Morizumi S, et al. Hybrid stenting therapy for dysphagia aortica with Rokitansky's diverticulum concomitant with thoracic aortic aneurysm. Eur J Cardiothorac Surg. 2015;47:e229-31.

69. Savlania A, Viswanathan S, Pitchai S, et al. Dysphagia aortica due to penetrated aortic ulcer. Eur J Cardiothorac Surg. 2015;48:337.

70. Ma X, Ma Y-T, Liu A-H, et al. Traumatic aortic aneurysm diagnosed by computed tomography angiography in a 22- year-old man presenting with progressive dyspnea and dysphagia. Int J Cardiovasc Imaging. 2016;32:1323-4.

71. Pitchai S, Goura P, Savlania A, et al. Dysphagia aortica: diagnostic dilemma and therapeutic paradigm. Indian J Vasc Endovasc Surg. 2016;3:45.

72. Beqari J, Lembo A, Critchlow J, et al. Pseudoachalasia secondary to thoracic aortic aneurysm. Ann Thorac Surg. 2017;103:e517-e8.

73. Choi H, Jeon U, Lee S, et al. A case of dysphagia aortica caused by a large thoracic aortic aneurysm. Soonchunhyang Med Sci. 2018;24:216-9.

74. Georgiadis GS, Argyriou C, Koutsoumpelis A, et al. Revised endografting for a giant descending thoracic aorta aneurysm due to synchronous type III/Ib endoleak, causing dysphagia. Ann Vasc Surg. 2018;53:272.e11-272.e17.

75. Gravito-Soares M, Gravito-Soares E, Souto P, et al. A rare and dangerous cause of dysphagia. Acta GastroenterolBelg. 2018:81:2017-8.

76. Kyaw WA, Lim CY, Khalil MAM, et al. A fatal case of Ortner's syndrome and dysphagia aortica secondary to rapidly expanding mycotic thoracic aortic aneurysm in a chronickidney disease patient. SAGE Open Med Case Rep. 2018;6:2050313X18799247.

77. Elsamman MK, Abdelaal UM, Omran MH, et al. Dysphagia aortica in a young patient with Behcet's disease: case report. Arab J Gastroenterol. 2019;20:145-7.

78. Dejaeger M, Lormans M, Dejaeger E, et al. Case report: an aortic aneurysm as cause of pseudoachalasia. BMC Gastroenterol. 2020;20:63.

79. Riambau V, Bockler D, Brunkwall J, et al. Management of descending thoracic aorta diseases. Clinical practice guidelines of the European society for vascular surgery (ESVS). Eur J Vasc Endovasc Surg. 2017;53:4-52.

80. Uno K, Koike T, Takahashi S, et al. Management of aortoesophageal fistula secondary after thoracic endovascular aortic repair: a review of the literature. Clin J Gastroenterol. 2017;10:393-402.

Publisher's Note Springer Nature remains neutral with regard to jurisdictional claims in published maps and institutional affiliations. 